\title{
Sushi in Cortez: Interdisciplinary Essays on Mesa Verde. Edited by David Taylor and Steve Wolverton. 2015. The University of Utah Press, Salt Lake City. 155 pp.
}

\author{
James R. Veteto ${ }^{1 *}$ \\ ${ }^{1}$ Department of Anthropology and Sociology, Western Carolina University, Cullowhee, NC, USA. \\ jirveteto@email.wcu.edu
}

Received May 11, 2017

Accepted May 24, 2017

OPEN $\partial_{\text {ACCESS }}$
DOI $10.14237 / \mathrm{ebl} .8 .1 .2017 .973$

Copyright (c) 2017 by the author(s) licensee Society of Ethnobiology. This is an open-access article distributed under the terms of the Creative Commons Attribution-NonCommercial 4.0 International Public License (https://creativecommons.org/licenses/by-nc/4.0), which permits non-commercial use, distribution, and reproduction in any medium, provided the original author and source are credited.

Sushi in Cortea: Interdisciplinary Essays on Mesa Verde, coedited by David Taylor and Steve Wolverton, documents one of the more unique academic experiments that I am aware of. It is a project that brought together six individuals to experience Mesa Verde, a bioregion of rich cultural and ecological complexity located in the Four Corners area of the southwestern United States. The idea was to get experts in different disciplines together in a significant archaeological and historical landscape, to reflect on and challenge each other's perspectives, hoping to forge new understanding and meaning in a type of edgework achieved through interdisciplinary banter, engagement, and outside-the-box thinking. The participants included Taylor, a writer and poet; Wolverton, an archaeologist and environmental scientist; Steve Bardolph, a photographer and graphic designer; Porter Swentzell, a Native educator from Santa Clara Pueblo in New Mexico; Melinda Levin, a documentary filmmaker; and Robert Figueroa, an environmental philosopher. The volume is a compendium of six essays written individually by project team members.

In "Making Sushi and Producing the Mesa Verde Project," Wolverton starts out the book with a selfreflective tone that is characteristic of the entire work. In cultural anthropology, we might term this 'reflexivity,' 'autoethnography,' and the work-as-awhole, 'multi-vocal.' The authors are not constrained by such categories. The main thrust of the volume includes much of what makes up contemporary cultural anthropology: deep reflections on what it means to be a researcher (e.g., Is it colonialism? Is it appropriation? Is it ethical?) in the contemporary global landscape of hotly contested terrains including identity politics, social justice, environmental degradation, cultural misunderstanding, and many other issues. Wolverton identifies himself as the 'glue' of the research team, handling many of the logistics, and makes a decision to silence himself as an archaeologist. He feels his expertise should be silenced in order to allow other narratives to manifest outside of the specialized knowledge of an archaeologist who works in the region. This selfcensoring is interesting in that it plays off another self -censoring that is practiced by Swentzell, the Native Puebloan expert, who by necessity of expectations and norms in his community, cannot share certain domains of knowledge with the group. We are left with a situation where the two foremost experts on Mesa Verde, Wolverton and Swentzell, are holding back. Indeed, as we learn later in his essay, Swentzell is initially suspicious of Wolverton (and rightly so, given the contentious history between Pueblo peoples and archaeologists) and as we learn in Wolverton's essay, he is intimidated and a bit threatened by the presence of Swenztell, whom he invited to the research team after colleagues and team members suggested that having a Native expert on board would be crucial to the project. Thankfully Wolverton followed their advice, as Swentzell ends up being the heart of the team, grounding the endeavor from an Indigenous perspective. The silencing is an effective strategy, as I suspect the project would have taken an entirely different (and less interesting, less exploratory) tone had it been led by an expert who 
was smug in his own archaeological construction of Mesa Verde history. However, the perspective from archaeology was not completely silent as Wolverton gave basic historical background lessons to the team in skype classroom pre-trip presentations and provided precursory introductions as the group arrived on-site at different Pueblo ruins. Nevertheless, there is a tension present in Wolverton's participation, which is different from but shares some solidarity with the tension that Swentzell experienced.

Wolverton argues extensively against the traditional Return On Investment (ROI) strategies of contemporary universities. He maintains that ROIs can stifle creativity and enjoyment in our work. Sushi in Cortez was initiated to send a group of scholars from different disciplines into the field to experience a landscape together. An entirely inductive exercise with no predictable outcome. Thus, it was nearly certain the project would never receive funding from institutions such as the National Science Foundation. Such as it was, the team was fortunate that the Center for the Study of Interdisciplinarity at University of North Texas (UNT), the home institution at the time of four project members (Taylor, Wolverton, Levin, Figueroa), was experimental enough to fund such a 'fuzzy' endeavor.

I agree with Wolverton's critique and disillusionment with ROIs, particularly as encouraged by funding agencies steeped in the sociologic of late vulgar neoliberal capitalism. However, as an applied scholar who believes that research in the current global context of crisis should be oriented toward environmental conservation and social justice (see Veteto and Lockyer 2008, 2015; Armstrong and Veteto 2015; Lockyer and Veteto 2013), I was struck by a vignette in this book's Prologue. Prior to going into the field, four members of the team (the UNT cohort mentioned above) organized an interdisciplinary panel on research as storytelling at the 2010 meeting of the Society of Ethnobiology in Victoria B.C., Canada. During the discussion, a First Nations man raised his hand and conveyed that he was offended because he "had come to this panel because his people have real-world problems and are trying to face current environmental crises; he had hoped to gain some tools from our panel to help him, and he felt he had gained nothing but anecdotes and intimation that he was clearly outside the academy, offered mainly from Texans" (p. xv). Ouch; biting and relevant criticism! It echoed some of the questions in my mind as I read this book. Here we have a team composed of an ethnobiologist, a poet, a philosopher, an Indigenous educator, a documentary filmmaker and photographer, and all we get out of the project is a cool place to hang out and some stories? What about applied collaborations to help conserve the biocultural heritage of Mesa Verde? Particularly, now, in the context of a US political regime that is threatening to dismantle the National Park system and desecrate sacred Native sites on treaty lands in the service of natural resource exploitation?

Such concerns were put to rest as I read further and learned about applied work inspired by the project being done by Bardolph and his students to promote Lake Superior herring as a local, sustainable food source and the work of three team members (Wolverton et al. 2016) calling for a self-determined "Pueblo Heritage Council" to be involved in all stages of planning and approval for archaeological projects to take place in the Mesa Verde region. Actual realworld results; this shows that providing an openended spaces for interdisciplinary reflection and interaction can make positive change even if that isn't the stated goal!

The second essay, by Steve Bardolph, is "Spinning in Circles." Bardolph created panoramic photographs which are stunning if seen in person or via the Sushi in Cortez webpage on the University of Utah website. Through his panoramic method, Bardolph tries to, “...emulate a Japanese garden, at once presenting an awe-inspiring and complete whole, as well as a lush tapestry of individual details spread across singular moments in time" (p. 30). His essay is presented as a "non-linear narrative of broken tiles" with the intent of creating "a colorful and informative picture of my interaction with interdisciplinarity and the Ancient Pueblo landscape and how my research, thoughts, and teaching have changed as a result" ( $p$. 31). Although I don't think he achieves non-linearity in his essay such as a reader might experience, for example, in reading Pueblo writers such as Leslie Marmon Silko (e.g., 2006) or Simon Ortiz (e.g., 1992), Bardolph's approach to photography is refreshingly insightful and potentially ground-breaking. His panoramic approach attempts to overcome both 2-D reality and the colonizing gaze:

Typical landscape photos, partly due to physics, the lens, and the nature of light, adopt a Renaissance perspective, flattening three-dimensional space into an ideal cropped 
window, much like a painting with one-point perspective. They can also adopt a "magisterial gaze" and can imply the ethos of "Manifest Destiny" the conquering journey West, especially when taken from scenic overlooks. They can obscure, ignore, or warp points of reality. Traditional photos can make the landscape (or cliff dwelling within it) into something of a commodity (p. 35).

To achieve the desired effect, Bardolph, from a carefully considered and chosen spot, starts at the horizon taking photographs in a clockwise spinning rotation, pivoting his feet a degree or two at a time. He takes 20-40 photos before he returns to his point of origin and completes a row. The camera is then pointed up or down a little bit and the process is completed again, up to fifteen different rows of pictures. At Butler Wash in the study region, Bardolph spun in place for more than an hour and took 600 photos. Later, back at his studio, he organized the images into a "shimmering overall perspective" and printed the re-construction into a 20 $\mathrm{ft}$ by $5 \mathrm{ft}$ collage. In addition to the weblink mentioned above, there is a full-color foldout in the book.

The result is spectacular. I am struck by how the 360-degree panorama, created by spinning in circles, enacts art that is noticeably, from my interpretation, closer to Indigenous world-views that typically see time as non-linear, either circular or spiraling. It is also closer to our everyday experience of reality as 3$\mathrm{D}$ and non-linear. I think Bardolph has created art that is loyal to the Mesa Verde landscape, and is perhaps more attuned to and respectful of the Native cultures that have lived there for thousands of years.

The third essay in the collection, "Two Trips to a Brewpub: Stories toward Interdisciplinary Thinking" is by David Taylor, a writer/poet steeped in the bioregional and eco-agrarian American poetry tradition. Those roots and influences appear immediately with a quote from Wendell Berry to start the essay and engagement with the words and ideas of Berry and eco-poet Gary Snyder throughout. Taylor's literary essay is wide-ranging as it explores interdisciplinarity, community, landscape, story, university architecture, the potential formation of a new type of university ('Astrofalfa'--_a utopian future university and joke shared by the group throughout), Monty Python, and craft beer. As an anthropologist-poet, the topic that struck me most was his insightful discussion of ethnopoetics and the challenges that field presents. He draws on Snyder's (1977) conceptualization of "The Politics of Ethnopoetics." Snyder's approach is that the urgent task of ethnopoetics is to translate the poetry of Indigenous people so that members of expansionist imperialist cultures can better understand their humanity and thus be less exploitative. Taylor takes Snyder's thinking a useful step forward when he begins to question his borrowing of topics from Swenztell and the Mesa Verde landscape and incorporating them into his poetry during the project. "In borrowing from him, I am also taking, and the poetry I offer in return heightens the risk of arrogance, imperialism, and, equally bad, the mistreatment of a friend" (p. 61). These are poignant concerns in the current (and any) socio-politicalcultural-context and is indicative of the challenges, concerns, and issues that each of the team members face in trying to both learn from and be respectful of Swentzell's culture and teachings. I assume the issues in this particular collaboration were worked out to the satisfaction of both parties as Swentzell and Taylor remain friends and have presented and published together on the results. The discussion of ethnopoetics and ethics is timely and important. Tensions and challenges and moments of illumination, camaraderie, and collaboration resulted in some beautiful poetry by Taylor, as evidenced in the last stanza of his poem "Butler Wash" (p. 69):

Water is the dream of rock,

not merging,

but already singular,

as air imagines itself in summer fire,

waiting on the wooded ridge above,

fire erodes to stone,

air follows the riverbed,

in spirals of entering or leaving,

a fluteplayer of lightning strikes

lifting birds and butterflies to flight.

In the fourth essay of the collection, "Irrigating Astroalfafa" by Porter Swentzell, we encounter an individual at the heart of the entire endeavor. Swentzell begins with an account of various waves of Euro-American invasions and colonialisms from Spanish to Mexican and American incursions. The resulting Pueblo society has experienced significant cultural loss (for example, in a 2005 survey, only 1 out of 300 children in his village spoke the Tewa language fluently) yet retains many of their traditional practices 
relative to other Native American tribes. Swentzell is from Santa Clara Pueblo (Khap'o Owingeh), one of six Tewa-speaking Pueblos in northern New Mexico. The Tewa people of Santa Clara number more than 3000 active members and trace their ancestry back to the archaeological sites in the Mesa Verde bioregion in tribal oral traditions.

Throughout the essays of other team members and this contribution by Swentzell, the reader encounters an individual of profound Native knowledge and deep moral authority. As mentioned above, Swentzell is bound by the ethical guidelines of his tribe to refrain from sharing certain domains of knowledge with outsiders, particularly key aspects of Tewa spirituality. These prohibitions stem from multiple sources, not the least being historical persecution experienced from Spanish, Mexican, and American Christians. The sharing of knowledge is not to be taken lightly. Historically, inappropriate cultural sharings by Pueblo people have resulted in a range of repercussions from their home communities, from ostracism and banishment to loss of property and even, in rare circumstances, death. The reader is left feeling fortunate to benefit from Swentzell's participation. What he has deemed appropriate to share is deeply insightful and of potential benefit to all of us currently living in a world-out-of-balance.

Swentzell offers unique insight about the archaeological sites the team is visiting. For him, the sacred Mesa Verde landscape consists of not merely 'sites' or 'ruins', but places imbued with living memory where people lived out rich and multifaceted lives for generations. Indeed, when such history is present, people are forever part of that place, meaning they are actually still there: "The ground still murmurs with the treading of their feet, and the air carries the sounds of their voices and songs" (p. 76). Swentzell offers a non-Western way of interacting with the landscape that is outside the normative experience of other team members. He interprets extreme weather events at their first two site visits (a rare tornado and unseasonable cold weather) not as amoral climatic occurrences, but opportunities to reflect, be humble, and break down barriers that may hinder the group from accomplishing their goal of interdisciplinary interaction and collaboration.

The playful term 'astrofalfa' emerged as the team encountered fields of green alfafa growing in the desert. They joked it would be the 'miracle crop' of the future (much as genetically modified corn 'is' today) that would solve any issue facing humanity, creating a myriad of commercial products-soft drinks, tires, houses, animal feed, and more. "'Astrofalfa' also represented a critique of the superficiality, commodification, and placelessness that seem to be pervasive in much of today's world" ( $p$. 81). Characteristic of the reflexive tone of the volume, Swentzell questions his own role in the commodification of culture and place, particularly as he had accepted cash payment for his role in the project. The fictional astrofalfa concept also serves as a jumping off point for some serious reflections on modernity and sustainability.

In 2012, the research team gathered for a public presentation of their project at the University of North Texas in Denton, 40 miles outside of Dallas at the northern apex of the Dallas-Fort Worth metroplex. This experience affected Swentzell more profoundly than the Pueblo sites he had been visiting since childhood. In his own words:

As I was leaving yesterday I was struck with a feeling of fear mixed with urgency. The endless rows of chain-restaurants interspersed with big-box stores looked not only formidable, but also unstoppable. As the plane banked over the urban sprawl my eyes were caught by the turquoise glitter of all the backyard swimming pools. Landing in New Mexico, I felt afraid for my homeland... seeing such an overt flexing of corporate power is rare for me. In Santa Clara Pueblo I can ignore many issues with relative ease. I am not used to being in a place where these issues are tenaciously present. I am left pondering what our endgame as human beings is (p. 87).

Again consistent with his (recognized, not claimed) role as the member of the group most likely to provoke profound moral questioning, Swentzell recognizes his own role in the consumption and destruction of the world (he is, after all, making the observation while simultaneously hurtling through the sky in an enormous metal object propelled by jet fuel) and points to the honest sharing of perspectives and collaboration experienced by the Mesa Verde research team as a positive model for dealing with the socioecological problems currently facing the world.

The fifth essay, "Location/Fraction: Documenting Storytelling in Mesa Verde" is by 
Melinda Levin. Through a documentary short film, Levin sought to tell 'a' story of Mesa Verde not 'the' story of Mesa Verde. She makes an interesting comparison between the collapse of Mesa Verde culture in 1300 and current socio-ecological crises:

...the impressive and evocative rise and collapse of a vast community haunts me with similarities of present-day environmental, agricultural, and self-identity challenges worldwide, including in this corner of the United States. I see a few too many parallels in terms of drought, external forces impacting successful agricultural practices, foreign species invasion, and the sustainability of cultural traditions. These challenges and our human response make them a good story (p. 92).

The film itself, Location/Fracture, available through the book website and on YouTube, is a nineminute collage of images: highways, cliff dwellings, mesa bluffs, rocks, the sun, highway dividing line, petroglyphs, clouds, desert rain pools, tourists, caves, highway signs, semi-trucks, creeks, and canyon panoramas. These images are accompanied by audio that I would describe as haunting/eerie punctuated briefly by NASA communication, a presidential statement on human rights, and Native flute music. There are various quotes from Mesa Verde team members throughout the film, focused variously on the juxtaposition of tradition and modernity, deprivileging archaeology, human-landscape interactions, and conflicting gendered park ranger narratives. The film is effective and reminds me of the experimental 1982 film Koyaanisqatsi by Godfrey Reggio that explores deep contrasts between traditional culture and modernity set to the music of Philip Glass. After watching Location/Fracture, the main theme I came away with was Dissonance, a theme reflected throughout the essays of Sushi in Corter:

The final essay of the collection is "Fire in the Rain: Exploring the Moral Terrains of Mesa Verde" by Robert Figueroa. Well known for his work on environmental justice (EJ), Figueroa explores related themes throughout. He does so in relationship to his interactions with Swentzell, which set the context for the essay.

Discussing much of what, as an ethnoecologist, I would consider TEK (Traditional Environmental Knowledge) and then going beyond into EJ, Figueroa constructs concepts to help us understand different aspects, stakeholders, and relationships inherent in the Mesa Verde landscape: moral terrains, environmental heritage, environmental identity, collective continuance (borrowed from Native scholar Kyle Whyte), transformative justice, principle of immediacy. To the non-specialist, these terms might seem like disciplinary jargon, but Figueroa explains them clearly and relates them well to topics in the book. I will use his concept of moral terrains (developed with Gordon Waitt) as an example. In short, landscapes in which we live or visit are terrains of multiple moral perspectives. The experience of Mesa Verde landscapes might be decidedly different for a Pueblo Native Elder, an archaeologist, a corporate CEO tourist, or park ranger. The essays in this volume illustrate different moral terrains experienced by team members according to their discipline, personal experience, and heritage. Figueroa uses this concept to enact what anthropologists might call multi -vocality to de-center dominate narratives. Furthermore, he foregrounds counternarratives embodied by Indigenous people (particularly Swentzell), and calls for an independent Indigenous council for consultation on archaeological projects conducted in the Mesa Verde Bioregion, from conception-not after key decisions have been made (see also Wolverton et al. 2016).

A central question alluded to and discussed throughout this volume centers on narratives surrounding the 'collapse' of Mesa Verde culture in 1300 AD. Archaeologists focus primarily on material and political explanations for collapse and subsequent migration southward: climate variability, drought, soil exhaustion, overpopulation, political conflict, warfare, etc. A Tewa perspective, as narrated by Swentzell, tells a different story: the people simply decided to leave because they had strayed too far from their original teachings and purposeful moral way of living. They sought to journey to a new place, creating a new society and world-in-balance. In terms of the concepts introduced by Figueroa, they left to create a new environmental heritage based on a transformation of their collective environmental identity.

The tensions between these two moral terrains, occupied by archaeologists and Pueblo Native Peoples, is discussed throughout Sushi in Cortez. As an outside reader, I am left wondering if they are in complete conflict. If, as Swenztell suggested in his essay, human actions are intimately interconnected 
with the environment and climate, could climate variability/change (see Wolverton et al. 2014), drought and other such variables be correlated with the degeneration of human moral society? Could factors such as overpopulation, political conflicts, and warfare also be signs that ancient Pueblo peoples have strayed from their original spiritual/moral teachings?

If this is the case, and archaeological and Native narratives are telling different aspects of the same story, I think the principle area of divergence lies in the agency of the actors. According to archaeological explanations, ancient Mesa Verde people had no choice but to vacate their communities as material factors forced their hand. In Pueblo accounts, the people chose to leave because they had strayed too far from the right way of living. In other words, they exercised agency in changing their way of life. If this is indeed so, and we are to take the Pueblo account seriously (which the authors do), then it's an historical example that provides hope for humanity as we currently face monumental social and ecological challenges. Perhaps we can choose a different way of life, just as the ancient people who left Mesa Verde did. And perhaps inter- and trans- disciplinary projects like Sushi in Cortez provide a partial roadmap that suggests listening, on an equal playing field, to people of varying backgrounds from different disciplines and widely divergent ways of thinking, might be a good place to start.

\section{References Cited}

Armstrong, C. G., and J. R. Veteto. 2015. Historical

Ecology and Ethnobiology: Applied Research for

Environmental Conservation and Social justice.

Ethnobiology Letters 6:5-7. DOI:10.14237/

ebl.5.2014.313.
Lockyer, J., and J. R. Veteto. 2013. Environmental Anthropology Engaging Ecotopia: Bioregionalism, Permaculture, and Ecovillages. Berghahn Books, New York, NY.

Ortiz, S. J. Woven Stone. 1992. University of Arizona Press, Tucson, AZ.

Silko, L. M. 2006. Ceremony, Penguin Classics Deluxe Edition. Penguin Books, New York, NY.

Snyder, G. 1977. The Old Ways: Six Essays. City Lights Books, San Francisco, CA.

Veteto, J. R., and J. Lockyer. 2008. Environmental Anthropology Engaging Permaculture: Moving Theory and Practice Toward Sustainability. Culture and Agriculture 30:47-58.

Veteto, J. R., and J. Lockyer. 2015. Applying Anthropology to What? Tactical/Ethical Decisions in an Age of Global Neoliberal Imperialism. Journal of Political Ecology 22:357-367. Available at: http:/ / jpe.library.arizona.edu/volume_22/

VetetoandLockyer.pdf. Accessed on May 11, 2017.

Wolverton, S., K. J. Chambers, and J. R. Veteto. 2014. Climate Change and Ethnobiology. Journal of Ethnobiology 34:273-275. DOI:10.2993/0278-077134.3.273.

Wolverton, S., R. M. Figueroa, P. Swentzell. 2016. Archaeology, Heritage, and Moral Terrains: Two Cases from the Mesa Verde Region. Ethnobiology Letters 7:23-31. DOI:10.14237/ebl.7.2.2016.695. 